- Letter

\title{
Hyperamylasemia Related to Sertraline
}

\author{
Mehmet Emin Ceylan, Alper Evrensel*, Barış Önen Ünsalver \\ Department of Psychiatry, Uskudar University, İstanbul, Turkey
}

\section{To the Editor}

Elevation of serum amylase level is usually associated with pancreatitis, ${ }^{1)}$ but $2 \%$ of cases are associated with medication. ${ }^{2)}$ Only 1 case of pancreatitis caused by sertraline has been reported. ${ }^{1)}$ Although it has been reported that selective serotonin reuptake inhibitors may rarely cause pancreatitis, ${ }^{2)}$ Elevated serum amylase levels associated with sertraline use in cases without pancreatitis has not been reported in the literature. To our knowledge, our case is the first report of hyperamylasemia related to sertraline.

A 35-year-old male patient with the diagnosis of recurrent depression was followed for over 10 years. He had been taking sertraline $25-50 \mathrm{mg} / \mathrm{d}$ for two years. Although the patient's biochemical test results were normal and he was clinically in remission, amylase levels started to increase slowly. At the twentieth month of treatment, her blood amylase level was $120 \mathrm{U} / \mathrm{L}$, and 4 months later, it was $160 \mathrm{U} / \mathrm{L}$ (normal range, 29 to $115 \mathrm{U} / \mathrm{L}$ ). There were no clinical or biochemical signs of pancreatitis. He did not have gallbladder stones and was not abusing alcohol. Sertraline was suspected to be the cause of increased amylase level. Sertraline was gradually discontinued over 2 months and was replaced with amitriptyline 50 $\mathrm{mg} / \mathrm{d}$. The amylase level started to decrease 20 days after discontinuation of sertraline, and slowly reached 90 U/L. However, his depression relapsed after discontinuation of sertraline. Lamotrigine $50 \mathrm{mg} / \mathrm{d}$ was added to the treatment regi- men, and amitriptyline dosage was increased to $75 \mathrm{mg} / \mathrm{d}$. In the third week of treatment, the patient was again in remission. Blood amylase level remained constant at $90 \mathrm{U} / \mathrm{L}$.

Asymptomatic hyperamylasemia can also occur without pancreatitis. ${ }^{3)}$ However, in these cases, the amylase level remains consistently high. In our case, the amylase level returned to normal after discontinuation of sertraline. The reason for hyperamylasemia associated with sertraline is not known. Clinicians should be aware of the possibility that sertraline may cause hyperamylasemia.

Sincerely,

\section{CONFLICT OF INTEREST}

No potential conflict of interest relevant to this article was reported.

\section{REFERENCES}

1. Malbergier A, de Oliveira Junior HP. Sertraline and acute pancreatitis: a case-report. Rev Bras Psiquiatr 2004;26:39-40.

2. Kvande KT, Madsen S. Selective serotonin uptake inhibitors and pancreatitis. Tidsskr Nor Laegeforen 2001;121:177-8.

3. Galassi E, Birtolo C, Migliori M, Bastagli L, Gabusi V, Stanghellini V, et al. A 5-year experience of benign pancreatic hyperenzymemia. Pancreas 2014;43:874-8. 